\title{
A Study on the Prediction of Realized Volatility of KOSPI 200 Index Option: Pre \& Post the Global Financial Crisis
}

\author{
Won Cheol Choi ${ }^{1} \&$ Sang Beom Park ${ }^{1}$ \\ ${ }^{1}$ Korea Aerospace University, Korea \\ Correspondence: Sang Beom Park, Korea Aerospace University, Korea. E-mail: psb@kau.ac.kr \\ Received: September 18, 2014 \\ Accepted: October 13, 2014 \\ Online Published: November 25, 2014 \\ doi:10.5539/ijef.v6n12p15 \\ URL: http://dx.doi.org/10.5539/ijef.v6n12p15
}

\begin{abstract}
KOSPI 200 Index Futures and KOSPI 200 Index Option are used as risk management tools as well as instruments to develop a new financial management product combined with other financial assets. Risk is the key consideration in management or investment and is measured by volatility. For this reason, it is critically important to predict the volatility of KOSPI 200 Index Option in option pricing and investment strategies. There are two widely used methods in measuring the option price; historical volatility using actual prices from the past and implied volatility predicting the value reflecting the current events. However, present option pricing may need to reflect the implied volatility that has been evaluated by the market already and therefore, if the market is efficient, implied volatility must be a good indicator for realized volatility. Since the global financial crisis that caused worldwide credit crunch lasted for an extended period with extreme volatility, this study separated the analysis period into the pre-crisis (January 2, 2003 through July 30, 2007), crisis period (August 1, 2007 through September 30, 2010) and post-crisis (October 1, 2010 through April 30, 2012). Based on the analysis, VKOSPI, a volatility index of KOSPI 200, demonstrated the most accurate predictability for the entire analytical period as well as for the pre-crisis period. During the post-crisis period, implied volatility was established as the most effective predictor. Concluding from various regression analyses, implied volatility itself showed a strong prediction capability even without adding other variables after the post-crisis period.
\end{abstract}

Keywords: risk, realized volatility, implied volatility, historical volatility, VKOSPI, predictability

\section{Introduction}

\subsection{Research Background and Motivation}

Stock index futures and stock index options are widely used as tools for investment in the stock market. Moreover, they are effective methods managing risks of stock market volatility. Options and futures do not only provide methods to manage various types of risk; they are also used as media to develop new types of financial products combined with other financial assets. For that reason, risk is the most essential factor of consideration in management or investment. Volatility is used as a metric scale. Volatility reflects uncertainty on future price of a certain asset and investors cannot be certain about changes in the future price of the asset if volatility becomes higher. In this context, precise predictions on the volatility of KOSPI 200 Future Index can serve as a basis of calculating option prices. According to Black-Sholes Pricing Model which is a representative theoretical approach on decisions over option pricing, among variables related to decisions over option pricing, there are some variables which investors can know at the point of investment. They are the price of the underlying asset, the exercise price, interest rate, and the time to the options' maturity. Thus, predicting volatility of the underlying asset is the core of the option pricing model. In this vein, many studies have been done to predict the volatility of the underlying asset.

A number of extant studies have eventually focused on finding out methods closer to the reality by alleviating the extant models by empirically testing superior models or methods in predicting future realized volatility. According to those methods, no models have illustrated consistent superiority because each study resulted in different conclusions in accordance with the types of underlying assets as well as research periods and research end-points.

Particularly, during the period when this study was going on, the international financial market and the Korean financial market went through tremendous turmoil due to credit crunch caused by the U.S. subprime mortgage 
crisis. In the aftermath, KOSPI Index dropped by 125.91 points (6.93\%) on August 16, 2007 compared to that of the previous day. It was the first case that KOSPI Index plunged by more than 100 points in a day. That started the representative implied volatility publicly announced by Korean Exchange (KRX) to skyrocket to $30 \% \sim 40 \%$. A phenomenal volatility which hit over $101 \%$ was recorded in 2008 .

Meanwhile, concerning methods predicting volatility, the most widely used are historical volatility which calculates real predictable variation in volatility from the price occurred in the past and implied volatility which induces predictive value on the predictable variation by reflecting changes taking place currently. Market evaluation on the value of options or the current market price of options already includes implied volatility evaluated by the market; if the market is efficient, implied volatility can serve as an efficient predictive index so this study aims to investigate predictive power on realized volatility of the index option market. Specifically, this study is to verify two hypotheses: the first purpose of this study is to find which is the better estimate among historical volatility, implied volatility and volatility index in predicting future realized volatility. The second one is to verify the hypothesis that volatility variables affiliated with implied volatility predict realized volatility better than historical volatility and the predictive power of implied volatility will be enhanced when a market shock occurs like a financial crisis compared to the pre-financial crisis because implied volatility will be an efficient predictive power on future realized volatility if the market is efficient.

Thus, this study divided the total analysis period of January 2, 2003 through April 30, 2012 to pre-and post-financial crises: the pre financial crisis is from January 3, 2003 to July 30, 2007 and the post-financial crisis is from October 1, 2010 when KOSPI 200 Index recovered 244.32 points to April 30, 2012. The period from August 1, 2007 to September 30, 2010 is sectionalized to the global financial crisis for empirical analyses in this study.

\section{Literature Review and Measurement Methods on Volatility}

\subsection{Literature Review}

Jorion (1995), Christensen and Prabhala (1998) and Fleming (1998) suggested that implied volatility had better results than past volatility in ex-post prediction; Canina and Figlewski (1993), Yang and Moon (1999), Ryu and Go (2008) argued that historical volatility has the best predictive power. Day and Lewis (1992) resulted in vague conclusions which did not tell which model is superior, suggesting that both implied volatility and past volatility contain future volatility. On the other hand, Corrado and Miller (2005), Gospodiniv, Gavala and Jiang (2006), and Lee and Jung (2006) proposed that volatility index has better predictive power.

\subsection{Types of Volatility and Measurement Methods}

\subsubsection{Historical Volatility}

The figures of past volatility of underlying asset prices are calculated from data on price changes over a given time period. Below is how to calculate the past volatility using mean square of daily rate of return over a given time period

$$
H V_{t}=\sqrt{250} \frac{1}{\tau} \sum_{i=0}^{\tau-1} r_{t-i}^{2}
$$

$\mathrm{HV}_{\mathrm{t}}$ : Historical Volatility;

$\mathrm{r}_{\mathrm{t}}:\left(\ln \left(\mathrm{S}_{\mathrm{t}}\right)-\ln \left(\mathrm{S}_{\mathrm{t}-1}\right)\right) \times 100 ;$

$\log$ rate of return of underlying asset price at $t$;

$\tau: 21$ business days;

Using the method above, $\sqrt{250}$ gets multiplied to convert to the annual rate.

In this study, past volatility of 21 days, which are monthly business days, is used as historical volatility for comparison analysis in consideration of concentration of option trades on the spread of recent months.

\subsubsection{Implied Volatility}

Characteristically, implied volatility has an advantage of reflecting the most recent information by estimating volatility which is being evaluated in the market and using the real market prices of options. Implied volatility is regarded to carry future volatility anticipated by market participants when the price is decided in the option market as it is volatility calculated by substituting all the parameter values and option market prices to the option pricing model except for volatility. Implied volatility can be calculated by the Black-Scholes option pricing model. In the Black-Scholes Model, implied volatility $(\sigma)$ embedded in the option price can be calculated by substituting KOSPI 200 except for volatility $(\sigma)$, the exercise price, interest rate, the time to the option's maturity 
and option's market price. Volatility calculated in this way implies the volatility of KOSPI 200 through option prices so it is called implied volatility and it refers to price volatility that makes the theoretical price of the Black-Scholes model and the market price equivalent. Daily data of KOSPI 200 options were used to calculate implied volatility and the spread of recent months and at-the-money option were used. However, it was difficult to find at-the-money option in reality so the smallest absolute value of moneyness was adopted. In order to calculate implied volatility, daily closing data at EUREX market linkage between October 29, 2012 and March 29, 2013 and the closing prices of CME night futures which were held contemporarily were used as the underlying asset; daily data of the annual yield on 91 day certificate of deposit (CD) provided by Korea Securities and Future Exchange (KRX) were used as interest rate; dividend index provided by KRX was used to calculate BSM implied volatility by adopting Newton-Raphson Method.

\subsubsection{Realized Volatility}

Realized volatility refers to volatility of underlying asset realized until now from a given point in the past. In order to measure realized volatility, used are standard deviation over a given time period and the mean square of yield rate.

According to recent studies on volatility, mean square is more adopted than standard deviation to calculate realized volatility. Thus, in this study, mean square on yield rate over a given time period was used to calculate realized volatility.

Below is the formula to calculate realized volatility using mean square of yield rate.

$$
R V_{t, \tau}=\sqrt{250} \frac{1}{\tau} \sum_{i=1}^{\tau} r_{t+i}^{2}
$$

$\mathrm{RV}_{\mathrm{t}, \tau}$ : Realized Volatility at $\mathrm{t}$;

$\mathrm{r}: \ln \left(\mathrm{S}_{\mathrm{i}}\right)-\ln \left(\mathrm{S}_{\mathrm{i}-1}\right), \log$ yield rate of underlying asset price;

$\tau$ : 21 business days.

\subsubsection{CBOE VIX}

It is safe to say that volatility index referring to volatility of future underlying asset(stock price index) embedded in the option price is the expected value measuring possibilities of change in stock price in the future which investors to the option market expect. Volatility index was first introduced in 1993 at U.S. CBOE (Chicago Board Options Exchanges) and VOX was modified on September 22, 2003 to introduce a new volatility index (VIX). In the second half of 2008 when the global financial crisis hit Korea and VIX (volatility index) reached an all-time high daily, the term became well known to Korean investors as well thanks to the media. Volatility index is generally negatively related to underlying asset (stock price index) so it is used as an important investment index for investors to perceive risks in the market situations. Moreover, it is widely used as an index to manage the stock market and establish strategy as well as research data.

\subsubsection{VKOSPI}

KRX (Korea Exchange) developed a volatility index fit to characteristics of the Korean market. It has released it to the public since April 13, 2009. In Korea, it is referred as "volatility index". To make investors from home and abroad comprehend the term more easily, "VKOSPI" (Volatility Index of KOSPI 200) which was coined from initials from volatility and KOSPI which is the representative brand of the Korean stock market.

VKOSPI basically adopts the method for fair variance swap for a theoretical model; however, the formula was developed independently to fit to the characteristics of the Korean market. VKOSPI is derived from the constituent of the recent and second month listed in the KOSPI 200 option market. In case of the roll-over of the settlement month remaining for thirty days or more, VKOSPI is estimated using only the constituent of the immediate delivery month because most transactions are concentrated in the constituent of the immediate delivery month. The options for calculating targets are the at-the-money (ATM) and out-of-the-money (OTM) options. Last auction price is used; if the last auction price is not available, option base price is used. In estimating, if the option for listing is considered to be lacking, the Black \& Scholes option pricing model is used to complement the estimated option. Concerning roll-over the base monthly constituent, the constituent of the immediate month is replaced with that of the second month on four trading days prior to the trading day for the constituent of the immediate month; the constituent of the second month is replaced with that of the third month. On the other hand, in consideration of the stability of the index, VKOSPI calculation is made beginning 15 minutes after the opening of the option market so time of calculation is from 09:15 to 15:15 and the calculation period is every 30 seconds because there are some item which do not achieve a traded price and the index may 
drop abruptly.

\subsubsection{Volatility of U.S. S\&P500}

The economic situation in the U.S. market affects all around the world, more particularly Asian stock markets. These days, Asian stock markets move similarly to the U.S. stock market. Specifically, in case of the nighttime KOSPI future market open at the same time of that of the U.S. stock market, it is expected for volatility of the U.S. index to have significant effects.

\section{Model and Empirical Analyses}

\subsection{Research Model}

This study aims to find out through analysis which is more accurate in predicting future realized volatility among historical volatility, implied volatility and volatility index (VKOSPI). Under circumstances of high levels of volatility due to the global financial crisis which extant studies have not dealt with, it is to analyze whether there have been changes in variables with accurate predictability compared to that of the pre-crisis period. In particular, the current market price of options includes implied volatility evaluated in the market; if the market is efficient, implied volatility can be an efficient predictive value so this study aims to verify hypotheses that volatility affiliated with implied volatility predicts realized volatility better than historical volatility and the predictive power of implied volatility will be enhanced when a shock occurs at the market like a financial crisis, compared to the pre-financial crisis.

Univariate and multivariate regression analyses were used to find out predictive and explanatory power on realized volatility (RV), such variables in Korea as historical volatility (HV), implied volatility, and volatility index (VKOSPI).

Above all, univariate regression was used to analyze information on explanation and predictive power of realized volatility. Below is the formula (3) for regressions.

$$
R V_{t}=a_{0}+a_{1} V_{i, t}+e_{t}
$$

$\mathrm{RV}_{\mathrm{t}}$ : Realized volatility during t period;

$\mathrm{V}_{\mathrm{i}, \mathrm{t}}$ : During $t$ period, historical volatility (HV), call mean implied volatility (CIV), put implied volatility (PIV), Representative implied volatility (IV), volatility index (VKOSPI), U.S. volatility index (VIX).

Next, there are various approaching methods of multivariate regression. Generally speaking, three methods are used in accordance with the purpose of use. Since this study is supposed to satisfy both explanations and predictions, stepwise multiple regression was adopted. Stepwise multiple regression is a way of adding variables with the best predictors (forward entry) and changes of F-statistic becomes statistically insignificant at $5 \%$ after including variables, variables get excluded.

Additionally, multicollinearity is a statistical phenomenon which frequently occurs with multivariate regression. It lowers reliability of regression because two or more predictor variables in a multiple regression model are highly correlated. As an indicator of multicollinearity, the variance inflation factor (VIF) is used in most cases. A VIF of 10 or higher implies that multicollinearity exists with the concerned variables.

Below is the regression model formula (4) for multivariate regression

$$
R V_{t}=a_{0}+\sum_{i=1}^{n} a_{i} V_{i, t}+e_{t}
$$

$\mathrm{RV}_{\mathrm{t}}$ : Realized volatility during $\mathrm{t}$;

$\mathrm{V}_{\mathrm{i}, \mathrm{t}}$ : During t period, historical volatility (HV), call mean implied volatility (CIV), put implied volatility (PIV), Representative implied volatility (IV), volatility index (VKOSPI), U.S. volatility index (VIX)

Determined coefficients of the regression line reflect the degree explaining the movement of realized volatility by predictors given by each volatility variable. After all, in the method of comparing each volatility variable and predictive power, whether predictive power of independent variables is statistically significant or not and whether determined coefficient values are greater than comparison targets or not will be the evaluation standard.

\subsection{Data for Analysis Target}

In this study, the total period used to calculate each volatility variable is from November 28, 2002 to May 30, 2012. The closing data of daily KOSPI 200 of Korea Exchange (KRX) were used to estimate realized volatility. In the same way, the closing data of daily KOSPI 200 were used to estimate historical volatility. For implied volatility, daily call mean implied volatility, put mean implied volatility and representative implied volatility announced at Korea Exchange (KRX) were used while VKOSPI data announced at Korea Exchange (KRX) 
were used for volatility index. Based on the date, VIX which is U.S. volatility index opens in the U.S.A. after Korea Exchange closes, so the volatility of U.S stock index on the previous day seems higher predictive power than that of the same day so this study adopted one-day lagged values of VIX index. Moreover, the opening date of U.S. stock market is not the same as that of Korean stock market so opening dates which did not match to the Korean stock market were eliminated. Moreover, opening dates which existed in Korea only but did not exist in the U.S.A. were substituted by the average values of the pre, post-average values.

In this study, the period for analysis is from January 2, 2003 to April 30, 2012. As mentioned in the introduction, starting from August 2007 when the U.S. subprime mortgage crisis went serious, this study divided the period of analyses to three periods: the pre-financial crisis which was from January 2, 2003 to July 31, 2007; the financial crisis period which was from August 1, 2007 when the subprime crisis hit the market seriously to September 30, 2010; the post-financial crisis is from October 1, 2010 when KOSPI 200 Index recovered 244.32 points that was the index point of July 30, 2007 when the financial crisis began to April 30, 2012. Predictive power on each volatility variable was compared and analyzed through univariate and multivariate regression analyses.

\subsection{Basic Statistics and Analysis on Correlations between Each Volatility Variable}

\subsubsection{Basic Statistics}

Before relations on predictability of realized volatility were investigated, basic statistics on each variable were found out. Basic statistics for the total period for analysis from January 2, 2003 to April 30, 2012 was summarized in Table 1.

Table 1. Basic statistics on each variable

\begin{tabular}{lllllllll}
\hline & Mean & Median & Max & Min & Std.Dev & Skewness & Kurtosis & No. of observations \\
\hline RV & $39.09 \%$ & $24.93 \%$ & $485.81 \%$ & $3.81 \%$ & 49.88 & 4.96 & 35.97 & 2279 \\
HV & $39.43 \%$ & $25.20 \%$ & $485.81 \%$ & $3.81 \%$ & 49.82 & 4.96 & 36.00 & 2279 \\
CIV & $22.68 \%$ & $19.9 \%$ & $83.9 \%$ & $6.1 \%$ & 9.83 & 2.4 & 11.37 & 2279 \\
PIV & $26.49 \%$ & $24 \%$ & $102.5 \%$ & $6.5 \%$ & 10.38 & 2.32 & 11.99 & 2279 \\
IV & $24.51 \%$ & $21.8 \%$ & $101 \%$ & $8.6 \%$ & 10.15 & 2.53 & 12.87 & 2279 \\
VKOSPI & $25.58 \%$ & $22.98 \%$ & $89.3 \%$ & $14.15 \%$ & 9.59 & 2.37 & 11.15 & 2279 \\
VIX & $21.15 \%$ & $18.45 \%$ & $80.86 \%$ & $9.89 \%$ & 10.20 & 2.10 & 8.88 & 2279 \\
\hline
\end{tabular}

Note. RV: realized volatility, HV: historical volatility, CIV: call mean implied volatility, PIV: put mean implied volatility, IV: representative implied volatility, VKOSPI: (Korean) volatility index, VIX: (U.S.) volatility index.

When means of each variable were looked into, historical volatility had the highest value, $39.43 \%$ followed by realized volatility and put mean implied volatility. The average value of representative implied volatility and that of volatility index were lower than that of realized volatility. Moreover, realized volatility had the highest standard deviation, 49.88 followed by historical volatility. Korean volatility index (VOKSPI) had the lowest, 9.59 .

In order to find out whether each volatility variable had a normal distribution or not, when skewness testing the asymmetry of the probability distribution and kurtosis testing whether the data are peaked or flat relative to a normal distribution were looked into, all of them had high values of skewness. So, they were right skewed, not a normal distribution. However, concerned variables need to have a normal distribution to carry out regression tests so they were log converted to make them have a normal distribution as illustrated in Table 2.

Table 2. Basic statistics after log conversion

\begin{tabular}{lllllllll}
\hline & Mean & Median & Max & Min & Std.Dev & Skewness & Kurtosis & No. of observations \\
\hline RV & $3.2888 \%$ & $3.2164 \%$ & $6.1858 \%$ & $1.3374 \%$ & 0.7945 & 0.6367 & 3.6122 & 2279 \\
HV & $3.3020 \%$ & $3.2269 \%$ & $6.1858 \%$ & $1.3374 \%$ & 0.7919 & 0.6110 & 3.6058 & 2279 \\
CIV & $3.0517 \%$ & $2.9907 \%$ & $4.4296 \%$ & $1.8082 \%$ & 0.3549 & 0.8359 & 4.1096 & 2279 \\
PIV & $3.2171 \%$ & $3.1780 \%$ & $4.6298 \%$ & $1.8718 \%$ & 0.3315 & 0.6913 & 4.0742 & 2279 \\
IV & $3.1360 \%$ & $3.0819 \%$ & $4.6151 \%$ & $2.1517 \%$ & 0.3373 & 0.9016 & 4.2859 & 2279 \\
VKOSPI & $3.1892 \%$ & $3.1346 \%$ & $4.4920 \%$ & $2.6497 \%$ & 0.3075 & 1.0514 & 4.3014 & 2279 \\
VIX & $2.9634 \%$ & $2.9150 \%$ & $4.3927 \%$ & $2.2915 \%$ & 0.4009 & 0.7976 & 3.3743 & 2279 \\
\hline
\end{tabular}

Note. RV: realized volatility, HV: historical volatility, CIV: call mean implied volatility, PIV: put mean implied volatility, IV: representative implied volatility, VKOSPI: (Korean) volatility index, VIX: (U.S.) volatility index. 
As seen in Table 2, through a log conversion of variables, skewness of each variable became close to 0 while kurtosis became close to 0 . Although each variable did not have perfect normal distribution, it was close to normal distribution. So, it will be analyzed. Moreover, when the average of the variables converted to log were looked into, historical volatility had the highest value, $3.3020 \%$, followed by realized volatility and put mean implied volatility. The average value of representative implied volatility and that of volatility index were lower than that of realized volatility. Furthermore, realized volatility showed the highest standard deviation, 0.7945 , followed by historical volatility, and U.S. volatility index (VIX). Korean volatility index (VKOSPI) had the lowest value, 0.3075 .

\subsubsection{Correlation Analysis}

Before regression analysis, correlation analysis between variables was implemented to find out overall relations. Below is the result of analyzing correlations between variables.

Table 3. Correlations between variables

\begin{tabular}{llllllll}
\hline & RV & HV & CIV & PIV & IV & VKOSPI & VIX \\
\hline RV & 1.0000 & & & & & & \\
HV & 0.7021 & 1.000 & & & & & \\
CIV & 0.7188 & 0.8760 & 1.000 & & & & \\
PIV & 0.6917 & 0.8388 & 0.8914 & 1.000 & & & \\
IV & 0.7262 & 0.8742 & 0.9692 & 0.9696 & 1.000 & & \\
VKOSPI & 0.7346 & 0.9032 & 0.9446 & 0.9151 & 0.9533 & 1.000 & \\
VIX & 0.5816 & 0.6822 & 0.7422 & 0.6127 & 0.6885 & 0.7690 & 1.000 \\
\hline
\end{tabular}

According to the result of correlation analysis, correlation with realized volatility was the highest with volatility index (VKOSPI), followed by representative volatility (IV), call mean implied volatility (CIV), historical volatility (HV), put mean implied volatility (PIV) and U.S. volatility (VIX). Through this result, it was confirmed that the group of implied volatility had higher correlation coefficients than historical volatility.

\subsection{Regression Analysis}

In this chapter, predictive power and explanatory power of such Korean variables as historical volatility, implied volatility, and volatility index towards realized volatility were comparatively analyzed through univariate regression as well as multivariate regression.

Plus this study divided the total period between January 2, 2003 and April 30, 2012 to pre- and post-financial crisis periods and the financial crisis period for comparative analysis: the pre financial crisis period is from January 2, 2003 to July 31, 2007; the financial crisis period is from August 1, 2003 when the subprime mortgage crisis hit the market seriously to September 30, 2010; the post-financial crisis period is October 1, 2010 to April 30,2012 when the stock prices recovered to the level of the pre financial crisis period.

\subsubsection{Univariate Regression Analysis}

Table 4 is the result of univariate regression analysis for the period of pre-global financial crisis (from January 2 , 2003 to July 31,2007$)$.

Table 4. Results of testing predictive power of each volatility variable on realized volatility during the pre-financial crisis period

\begin{tabular}{|c|c|c|c|c|c|c|c|}
\hline Variable & (Constant) & Vol & F-statistic & $\begin{array}{l}\text { Prob } \\
\text { (F-statistic) }\end{array}$ & $\begin{array}{l}\text { Adjusted } \\
\text { R-squared }\end{array}$ & RMSE & $\begin{array}{l}\text { Durbin } \\
\text {-Watson stat }\end{array}$ \\
\hline $\mathrm{HV}$ & $\begin{array}{l}1.1795 \\
(0.0000)\end{array}$ & $\begin{array}{l}0.6259 \\
(0.0000)\end{array}$ & 667.74 & 0.0000 & 0.3742 & 0.5319 & 0.0422 \\
\hline CIV & $\begin{array}{l}-1.2340 \\
(0.0000)\end{array}$ & $\begin{array}{l}1.4757 \\
(0.0000)\end{array}$ & 633.99 & 0.0000 & 0.3621 & 0.5370 & 0.1734 \\
\hline PIV & $\begin{array}{l}-1.2601 \\
(0.0000)\end{array}$ & $\begin{array}{l}1.3748 \\
(0.0000)\end{array}$ & 437.68 & 0.0000 & 0.2821 & 0.5700 & 0.1566 \\
\hline IV & $\begin{array}{l}-1.6752 \\
(0.0000)\end{array}$ & $\begin{array}{l}1.5599 \\
(0.0000)\end{array}$ & 595.61 & 0.0000 & 0.3478 & 0.5430 & 0.1574 \\
\hline
\end{tabular}




\begin{tabular}{llllllll}
\hline VKOSPI & -2.6516 & 1.8578 & 759.35 & 0.0000 & 0.4048 & 0.5188 & 0.0467 \\
& $(0.0000)$ & $(0.0000)$ & & & & \\
VIX & -1.1883 & 1.6074 & \multirow{2}{*}{635.64} & 0.0000 & 0.3627 & 0.5368 & 0.0514 \\
\hline
\end{tabular}

Note. Values in parentheses refer to p-value.

As seen in Table 4, all the F-statistic values of univariate regression were significantly less than $1 \%$ so it was confirmed that all the univariate models were statistically significant. Moreover, all the regression coefficients were also statistically significant so interpretations were reasonably acceptable as well. The Durbin-Watson statistic was close to 0 so no heteroskedastic error was found.

In addition, according to the result of analyzing predictive power towards realized volatility, volatility index (VKOSPI) had the highest adjusted R-squared (Adj. $-\mathrm{R}^{2}$ ), 0.4048. According to the analysis on RMSE (root mean square error), it had the lowest value of error, 0.5188 . The volatility with the second highest predictive power was historical volatility whose adjusted R-squared was 0.3742 and RMSE was 0.5319 . The third one was U.S. volatility index (VIX) whose adjusted R-squared was 0.367and RMSE was 0.5368. The fourth one was call mean implied volatility whose adjusted R-squared was 0.3621 and RMSE was 0.5370 , followed by representative implied volatility (IV) and put mean implied volatility (PIV). In conclusion, during the pre-financial crisis period, VKOSPI had the highest predictive power for realized volatility.

Using the same method above to analyze the global financial crisis period which was ignited by the subprime mortgage loan crisis, following Table 5 is the result of univariate regression from August 1, 2003 when the global financial crisis hit Korean stock market directly to September 30 when KOSPI 200 was recovered by 244.32 points which was the index of July 31, 2003.

Table 5. Results of testing predictive power of each volatility variable towards realized volatility during the financial crisis period

\begin{tabular}{|c|c|c|c|c|c|c|c|}
\hline Variable & (Constant) & Vol & F-statistic & $\begin{array}{l}\text { Prob } \\
\text { (F-statistic) }\end{array}$ & $\begin{array}{l}\text { Adjusted } \\
\text { R-squared }\end{array}$ & RMSE & $\begin{array}{l}\text { Durbin } \\
\text {-Watson stat }\end{array}$ \\
\hline $\mathrm{HV}$ & $\begin{array}{l}0.7754 \\
(0.0000)\end{array}$ & $\begin{array}{l}0.7683 \\
(0.0000)\end{array}$ & 998.84 & 0.0000 & 0.5591 & 0.5733 & 0.0507 \\
\hline CIV & $\begin{array}{l}-2.0069 \\
(0.0000)\end{array}$ & $\begin{array}{l}1.7280 \\
(0.0000)\end{array}$ & 1368.70 & 0.0000 & 0.6348 & 0.5218 & 0.1438 \\
\hline PIV & $\begin{array}{l}-2.3417 \\
(0.0000)\end{array}$ & $\begin{array}{l}1.7824 \\
(0.0000)\end{array}$ & 1378.88 & 0.0000 & 0.6365 & 0.5206 & 0.1929 \\
\hline IV & $\begin{array}{l}-2.2390 \\
(0.0000)\end{array}$ & $\begin{array}{l}1.7754 \\
(0.0000)\end{array}$ & 1518.02 & 0.0000 & 0.6584 & 0.5046 & 0.1490 \\
\hline VKOSPI & $\begin{array}{l}-2.9202 \\
(0.0000)\end{array}$ & $\begin{array}{l}1.9367 \\
(0.0000)\end{array}$ & 1352.76 & 0.0000 & 0.6320 & 0.5238 & 0.0699 \\
\hline VIX & $\begin{array}{l}-1.4796 \\
(0.0000)\end{array}$ & $\begin{array}{l}1.5214 \\
(0.0000)\end{array}$ & 431.78 & 0.0000 & 0.3537 & 0.6941 & 0.0425 \\
\hline
\end{tabular}

Note. Values in parentheses refer to p-value.

According to univariate regression for the period of the financial crisis, all the F-statistic values of univariate regression were significantly less than $1 \%$ so it was confirmed that all the univariate models were statistically significant. The Durbin-Watson statistic was close to 0 so no heteroskedastic error was found.

According to the result of analyzing predictive power towards realized volatility, unlike the previous analysis for the period of pre-financial crisis, representative implied volatility (IV) had the highest adjusted R-squared (Adj.-R), 0.6584. According to the analysis on RMSE (root mean square error), it had the lowest value of error, 0.5046 . The volatility with the second highest predictive power was put mean implied volatility (PIV) whose adjusted R-squared was 0.6365 and RMSE was 0.5206 . The third one was call mean implied volatility (CIV) whose adjusted R-squared was 0.6348 and RMSE was 0.5218 . The fourth one was volatility index (VKOSPI) which had the highest predictive power during the pre-financial crisis period, followed by historical volatility (HV) and U.S. volatility index (VIX). Particularly, compared to the period of pre-financial crisis, the explanatory power and predictive power of a group of implied volatility became higher after the financial crisis. It was found 
that the explanatory power was enhanced to $50 \% \sim 60 \%$ during the period of post-financial crisis from $30 \% \sim 40 \%$ during the period of pre-financial crisis.

Lastly, the following Table 6 is the result of univariate regression analysis from October 1, 2010 when the price index of stocks recovered to the level of the pre-financial crisis to April 30, 2012.

Table 6. Results of testing predictive power of each volatility variable on realized volatility during the post-financial crisis period

\begin{tabular}{|c|c|c|c|c|c|c|c|}
\hline Variable & (Constant) & Vol & F-statistic & $\begin{array}{l}\text { Prob } \\
\text { (F-statistic) }\end{array}$ & $\begin{array}{l}\text { Adjusted } \\
\text { R-squared }\end{array}$ & RMSE & $\begin{array}{l}\text { Durbin } \\
\text {-Watson stat }\end{array}$ \\
\hline $\mathrm{HV}$ & $\begin{array}{l}1.1119 \\
(0.0000)\end{array}$ & $\begin{array}{l}0.6560 \\
(0.0000)\end{array}$ & 306.73 & 0.0000 & 0.4498 & 0.6283 & 0.0281 \\
\hline CIV & $\begin{array}{l}-1.3916 \\
(0.0000)\end{array}$ & $\begin{array}{l}1.5414 \\
(0.0000)\end{array}$ & 268.97 & 0.0000 & 0.4174 & 0.6465 & 0.0797 \\
\hline PIV & $\begin{array}{l}-2.0770 \\
(0.0000)\end{array}$ & $\begin{array}{l}1.7070 \\
(0.0000)\end{array}$ & 367.89 & 0.0000 & 0.4952 & 0.6018 & 0.1338 \\
\hline IV & $\begin{array}{l}-1.8693 \\
(0.0000)\end{array}$ & $\begin{array}{l}1.6725 \\
(0.0000)\end{array}$ & 345.79 & 0.0000 & 0.4797 & 0.6109 & 0.0974 \\
\hline VKOSPI & $\begin{array}{l}-3.0588 \\
(0.0000)\end{array}$ & $\begin{array}{l}2.0232 \\
(0.0000)\end{array}$ & 332.67 & 0.0000 & 0.4700 & 0.6166 & 0.0510 \\
\hline VIX & $\begin{array}{l}-3.1372 \\
(0.0000)\end{array}$ & $\begin{array}{l}2.0701 \\
(0.0000)\end{array}$ & 338.73 & 0.0000 & 0.4745 & 0.6140 & 0.0716 \\
\hline
\end{tabular}

Note. Values in parentheses refer to p-value.

According to regression analysis for the period of post-financial crisis, all the F-statistic values of univariate regression were significantly less than $1 \%$ like those of the pre-financial crisis and financial crisis periods so they were statistically significant. No heteroskedastic error was detected. According to the result of analyzing predictive power on realized volatility, unlike the previous analysis for the period of the financial crisis, put mean implied volatility (PIV) had the highest adjusted R-squared, 0.4592. According to the analysis on RMSE (root mean square error), it had the lowest value of error, 0.6018. The volatility with the second highest predictive power was U.S. volatility index (IV) whose adjusted R-squared was 0.4797 and RMSE was 0.6109. The third one was U.S. volatility index (VIX) whose adjusted R-squared was 0.4745 and RMSE was 0.6140. The fourth one was volatility index (VKOSPI) which had the highest predictive power during the pre-financial crisis period, followed by historical volatility (HV) and call mean implied volatility (CIV)

Table 7. Verification on predictive power during the period of pre financial crisis through multivariate regression

\begin{tabular}{lllllllll}
\hline & (Constant) & VKOSPI & HV & VIX & CIV & IV & Adjusted R Square & RMSE \\
\hline coefficient & -2.6516 & 1.8578 & & & & & & \\
p-value & 0.000 & 0.000 & & & & 0.4048 & 0.5188 \\
VIF & & 1.000 & & & & & \\
coefficient & -1.5573 & 1.2744 & 0.2313 & & & & \\
p-value & 0.000 & 0.000 & 0.000 & & & & \\
VIF & & 4.56 & 4.56 & & & & \\
coefficient & -1.2417 & 0.4251 & 0.2941 & 0.7929 & & & \\
p-value & 0.000 & 0.015 & 0.000 & 0.000 & & & \\
VIF & & 7.25 & 4.68 & 2.80 & & & \\
coefficient & -1.2114 & 0.2070 & 0.2820 & 0.7703 & 0.2525 & & & \\
p-value & 0.000 & 0.3110 & 0.000 & 0.000 & 0.390 & & 0.4482 & \\
VIF & & 9.89 & 5.02 & 4.75 & 2.84 & & & \\
coefficient & -1.1695 & 0.3047 & 0.2794 & 0.7536 & 0.4419 & -0.2769 & & \\
p-value & 0.000 & 0.166 & 0.000 & 0.000 & 0.027 & 0.232. & 0.4485 & \\
VIF & & 15.51 & 13.46 & 11.47 & 4.76 & 2.89 & & 0.4994 \\
\hline
\end{tabular}




\subsubsection{Multivariate Regression Analysis}

In this study, stepwise multiple regression which is one of multivariate regression methods was implemented. The variance inflation factor (VIF) was used as an indicator of multicollinearity which is frequently observed in multivariate regression. When the value of VIF is 10 or higher, it is interpreted as a severe multicollinearity.

The result of multivariate regression analysis during the pre financial crisis period (January 2, 2003 through July 31 2007) is in Table 7.

According to the result of multivariate regression analysis comprehending all volatility variables for analysis for the period of pre financial crisis, the model added with volatility index (VKOSPI) and U.S. volatility index (VIX) which had the highest predictive power in the univariate regression test had the highest predictive power. The explanatory power was enhanced to $44.66 \%$ from $40.48 \%$ and RMSE was lowered to 0.5002 from 0.5188 , which proves higher predictive power. Multicollinearity was not observed. However, when call mean implied volatility was added, the p-value became out of the significant level and multicollinearity took place.

Table 8 is the result of considering all volatility variables during the financial crisis period (August 1, 2007 through September 30, 2010).

Table 8. Verification of predictive power during the financial crisis period through multivariate regression

\begin{tabular}{lllllllll}
\hline & (Constant) & IV & PIV & CIV & VKOSPI & HV & Adjusted R Square & RMSE \\
\hline coefficient & -2.2390 & 1.7754 & & & & & & \\
p-value & 0.000 & 0.000 & & & & 0.6584 & 0.5046 \\
VIF & & 1.000 & & & & & \\
coefficient & -2.2661 & 1.6278 & 0.1538 & & & & \\
p-value & 0.000 & 0.000 & 0.509 & & & & & \\
VIF & & 25.04 & 25.04 & & & & & \\
coefficient & -2.2821 & 1.3758 & 0.2590 & 0.1522 & & & \\
p-value & 0.000 & 0.029 & 0.444 & 0.668 & & & \\
VIF & & 190.76 & 61.64 & 52.75 & & & \\
coefficient & -2.3428 & 1.3817 & 0.1914 & 0.0813 & 0.1475 & & & \\
p-value & 0.000 & 0.029 & 0.591 & 0.828 & 0.546 & & 0.6578 & \\
VIF & & 190.81 & 68.37 & 58.52 & 23.13 & & & \\
coefficient & -2.1808 & 1.4212 & 0.1673 & 0.0328 & 0.0808 & 0.0465 & & \\
p-value & 0.000 & 0.025 & 0.640 & 0.931 & 0.754 & 0.410 & 0.6574 & \\
VIF & & 191.91 & 70.06 & 58.91 & 25.67 & 6.93 & & \\
\hline
\end{tabular}

According to multivariate regression analysis comprehending all volatility variables during the financial crisis period, representative implied volatility, which had the highest explanatory power in the univariate analysis, had a problem of multicollinearity. As a result, like the result of univariate regression analysis, representative implied volatility had the highest explanatory power and the predictive power on realized volatility.

At this point, when compared to the maximized significant explanatory power of multivariate regression during the period of pre financial crisis which was $44.66 \%$, the result of multivariate regression analysis during the financial crisis period, the explanatory power was enhanced up to $65.84 \%$ only with one volatility variable which was representative implied volatility (IV). Moreover, it was proved that that its predictive power was superior without increasing explanatory variables considerably.

Table 9 is the result of multivariate regression during the period of post-financial crisis (October 1, 2010 through April 30, 2012). 
Table 9. Verification of predictive power during the period of post-financial crisis through multivariate regression analysis

\begin{tabular}{|c|c|c|c|c|c|c|c|c|}
\hline & (Constant) & PIV & IV & VIX & VKOSPI & $\mathrm{HV}$ & Adjusted R Square & RMSE \\
\hline coefficient & -2.0770 & 1.7070 & & & & & & \\
\hline p-value & 0.000 & 0.000 & & & & & 0.4952 & 0.6018 \\
\hline VIF & & 1.000 & & & & & & \\
\hline coefficient & -2.0797 & 1.3644 & 0.353 & & & & & \\
\hline p-value & 0.000 & 0.001 & 0.367 & & & & 0.4950 & 0.6019 \\
\hline VIF & & 19.13 & 19.13 & & & & & \\
\hline coefficient & -2.8485 & 0.8503 & 0.2152 & 0.9039 & & & & \\
\hline p-value & 0.000 & 0.036 & 0.574 & 0.000 & & & 0.5132 & 0.5909 \\
\hline VIF & & 21.45 & 19.29 & 4.67 & & & & \\
\hline coefficient & -2.5636 & 0.8526 & 0.6088 & 1.0668 & -0.6412 & & & \\
\hline p-value & 0.000 & 0.036 & 0.225 & 0.000 & 0.225 & & 0.5138 & 0.5906 \\
\hline VIF & & 33.15 & 24.64 & 21.45 & 6.20 & & & \\
\hline coefficient & -1.3985 & 0.8439 & 0.5130 & 0.9957 & -1.0887 & 0.2370 & & \\
\hline p-value & 0.000 & 0.035 & 0.301 & 0.000 & 0.045 & 0.002 & 0.5250 & 0.5838 \\
\hline VIF & & 33.28 & 26.52 & 21.45 & 6028 & 4.79 & & \\
\hline
\end{tabular}

According to multivariate regression analysis including all volatility variables during the period of post-financial crisis, when representative implied volatility (IV) was added to put mean implied volatility (PIV), a problem of multicollinearity took place. As a result, like the result of the univariate regression analysis, put mean implied volatility had the highest explanatory power and the predictive power on realized volatility.

\section{Conclusion and Implications}

This study analyzed predictability of various types of volatility on realized volatility using historical volatility and a group of implied volatility variables, such as representative implied volatility, call mean implied volatility, put mean implied volatility and volatility index as well as U.S. volatility index as overseas information variable during the period of January 2, 2003 through April 30, 2012. Moreover, the period for analysis was divided for comparative analysis: the pre-financial crisis period is from January 3, 2003 to July 31, 2007; the financial crisis period is from August 1, 2007 when the subprime mortgage crisis hit the market seriously to September 30, 2007; the post-financial crisis period is October 1, 2010 to April 30, 2012 when the stock prices recovered to the level of the pre financial crisis period.

Above all, it was analyzed that which volatility explains better realized volatility through univariate regression on each volatility variable. Moreover, it was comparatively analyzed whether the predictive power of volatility variables to realized volatility which showed the highest predictive power according to the univariate regression can be enhanced by adding other variables to them through multivariate regression. Below is the summary of research results.

First, according to the result of the univariate regression analysis, VKOSPI which is volatility index had the highest predictive power for realized volatility during the period of pre financial crisis. In case of the financial crisis period, representative implied volatility (IV) had the highest predictive power, followed by put mean implied volatility and call mean implied volatility. During the period of post-financial crisis, put mean implied volatility had the highest predictive power, followed by representative implied volatility.

Second, according to the result of the multivariate regression during the financial crisis period, volatility index which had the highest predictive power in the univariate analysis had the highest predictive power when added with historical volatility and U.S. volatility index (VIX). However, when call mean implied volatility was added, a problem of multicollinearity occurred.

Third, according to the multivariate regression analysis during the financial crisis period, representative implied volatility which had the highest predictive power for realized volatility had enough explanatory and predictive power. When other independent variables were added, multicollinearity issues took place.

Fourth, according to the multivariate analysis result during the period of post-financial crisis, put mean volatility which had the highest predictive power in the univariate regression analysis had enough explanatory and predictive power. 
In conclusion, for the analysis period of ten years from January 2, 2003 to April 30, 2012, Korean volatility index (VKOSPI) had the highest predictive power for realized volatility of KOSPI 200 index option market for four years and seven months from January 2, 2003 to July 31, 2007. Moreover, it was found out that its predictive power was enhanced when added with historical volatility and U.S. volatility index. During the period of the financial crisis for three years and one month from August 1, 2007 to September 30, 2010, representative implied volatility had the highest predictive power for realized volatility while representative implied volatility had enough explanatory power. Moreover, during the period of post-financial crisis for one year and seven months from October 1, 2010 to April 30, 2012, put mean implied volatility without adding any other variables had the highest predictive power. It illustrates that the predictive power of implied volatility became higher predictive power than any other volatility variable as high levels of volatility continued after the emergence of the global financial crisis.

However, the financial crisis period in which high levels of volatility were maintained was only three years and one month in consideration of the total analysis period of ten years so further research in various fields is recommended to find out whether the switch of variables with the highest predictive power for realized volatility of KOSPI 200 index option from volatility index (VKOSPI) which had the highest predictive power before the financial crisis to a group of implied volatility like representative implied volatility and put mean implied volatility was caused by the general flow of the market or one-off happening under an unusual situation like the financial crisis.

Nevertheless, VKOSPI which is Korean volatility index was evaluated to have superior predictive power and a group of implied volatility indices was verified to have very excellent predictive power in a market with high levels of volatility due to an unexpected shock. So, they are expected to be used as a guideline for investors to decide investments in the future.

\section{References}

Canina, L., \& Figlewski, S. (1993). The informational content of implied volatility. The Review of Financial Studies, 6, 659-681. http://dx.doi.org/10.1093/rfs/6.3.659

Chang, K. H. (2001). A Research on Korean Option Market's Volatility Forecasting and Comparison of Forecasting Results. Korean Journal of Futures and Options, 51-79.

Choi, H. C., \& Han, S. H. (2009). Explanation of VKOSPI and Empirical Analysis. KRX Market, $28-32$.

Christensen, B. R., \& Prabhala, N. R. (1998). The relation between implied and realized volatility. Journal of Financial Economics, 50, 125-150. http://dx.doi.org/10.1016/S0304-405X(98)00034-8

Chung, J. R. (2009). Deviation and Application of Volatility Index(VIX) Using the KOSPI200 Options. Ph.D Dissertation, Sung Kyun Kwan Universlty.

Corrado, C., \& Miller, T. (2005). The forecast quality of CBOE implied volatility indexes. Journal of Futures Markets, 25, 339-373. http://dx.doi.org/10.1002/fut.20148

Day, T., \& Lewis, C. (1992). Stock market volatility and the information content of stock index options. Journal of Econometrics, 52, 267-287. http://dx.doi.org/10.1016/0304-4076(92)90073-Z

Fleming, J. (1998). The quality of market volatility forecasts implied by S\&P100 index option prices. Journal of Empirical Finance, 5, 317-345. http://dx.doi.org/10.1016/S0927-5398(98)00002-4

Gospodiniv, N., Gavala, A., \& Jiang, D. (2006). Forecasting volatility. Journal of Forecasting, 25, 381-400. http://dx.doi.org/10.1002/for.993

Hull, J., \& White, W. (1987). The pricing of options on assets with stochastic volatilities. Journal of Finance, 42, 281-300. http://dx.doi.org/10.1111/j.1540-6261.1987.tb02568.x

Jae, H. L., \& Je Ryun, C. (1976). Deviation and Analysis of Volatility Index in the KOPI200 Options. In H. Latane \& R. Rendleman (Eds.), Standard deviation of stock price ratios implied in option price. Journal of Finance, 31, 369-381. http://dx.doi.org/10.1111/j.1540-6261.1976.tb01892.x

Jae, H. L., \& Je Ryun, C. (2011). Forecasting Power of KOSPI200 Option Implied Volatility. Korean Journal of Futures and Options, 25-50.

Jorion, P. (1995). Rredicting volatility in the foreign exchange market. Journal of Finance, 50, 507-528. http://dx.doi.org/10.1111/j.1540-6261.1995.tb04793.x

Market. (2006). Korean Journal of Financial Studies, 35(2), 109-138. 
Whaley, R. E. (2000). The Investor Fear Gauge. Journal of Portfolio Management, 26, $12-17$. http://dx.doi.org/10.3905/jpm.2000.319728

Yang, S. K., \& Moon, S. J. (1999). The Implied Volatility and Realized Volatility of KOSPI200 Option. Korea Financial Association, 455-470.

Yoo, S., \& Jung, Y. K. (2009). A Research on Enhancing Forecasting Power for the Realized Volatility of KOSPI200. Korean Journal of Futures and Options, 17(1), 21-49.

\section{Copyrights}

Copyright for this article is retained by the author(s), with first publication rights granted to the journal.

This is an open-access article distributed under the terms and conditions of the Creative Commons Attribution license (http://creativecommons.org/licenses/by/3.0/). 